\title{
UNA TESIS IUSNATURALISTA (Y SANCIONADORA) PARA ERRADICAR LA PASIVIDAD DEMOCRÁTICA Y ELECTORAL EN MÉXICO
}

\section{Joaquin Ordoñez ${ }^{1}$}

\section{Resumen}

El iuspositivismo indica que debe existir sanción ante la omisión de conductas ordenadas y las tesis iusnaturalistas indican que lo justo ante una obligación es que se sancione su incumplimiento. De acuerdo con el mandato constitucional, el voto es una obligación, por tanto, debe existir una sanción para su no cumplimiento. Sin embargo, en México no existe tal sanción y se sufre de un alto índice de pasividad electoral (no solamente de abstencionismo electoral, que es una especie del género pasividad democrática), por ello, como una manera de solucionar el problema, se propone la tesis consistente en aplicar la sanción que con justicia debería corresponder para el caso de incumplimiento de la obligación de emitir el voto, lo anterior con base en los fundamentos del iusnaturalismo traducidos en juicio democrático, y con ello incluso satisfacer las categorías de prudencia, templanza y paz.

Palabras clave: Iusnaturalismo, iuspositivismo, democracia, pasividad democrática, elecciones.

\section{INTRODUCCIÓN}

Uno de los problemas más acuciantes que se sufren en México es el relacionado con el abstencionismo electoral, el cual ha sido preocupante, ${ }^{2}$ y más allá de un abstencionismo, se traduce en una pasividad democrática,

\footnotetext{
${ }^{1}$ Dr. en Derecho, Profesor e investigador de tiempo completo de la Facultad de Derecho de la Universidad Autónoma del Estado de México. Sus líneas de Investigación son: Derecho Constitucional, Teoría de la Democracia, Derecho Electoral. E-mail: joaquin.o@me.com

${ }^{2}$ No obstante, se debe tener en cuenta que en las recientes elecciones federales del 2018 en México hubo una interesante participación del electorado (con un 63.42\%), ya que, por citar un ejemplo, el partido político Movimiento de Regeneración
} 
ya que el ciudadano no solamente no está interesado en participar en las elecciones al no acudir a votar en el momento establecido para la jornada electoral, sino que además no quiere hacerlo ${ }^{3}$ de ninguna otra manera por la cual se pueda ejercer la democracia (por ejemplo, consultas ciudadanas, plebiscitos, solicitudes de transparencia, etc.). Esta situación de la realidad política y social contrasta con lo establecido en las leyes y, sobre todo, en la Constitución Política de los Estados Unidos Mexicanos, lo cual lleva a concluir que el sistema jurídico democrático (que debería estar diseñado para que la democracia y sus instrumentos sean ejercidos) contiene en sí mismo un problema derivado de la aplicación de normas jurídicas positivas que permiten o que no regulan adecuadamente la abstención o la pasividad democrática. Aunado a lo anterior, no debemos olvidarnos de que la democracia tiene como finalidad el logro y el mantenimiento de la paz de todos los hombres en sociedad, por lo que esa finalidad debe, lógicamente, ser incluida en los objetivos de sus mecanismos y en la propia esencia de sus postulados y principios.

Lo anterior significa que el problema mexicano (y de aquellos países en los que suceden fenómenos políticos y sociales similares) no radica exclusivamente en el abstencionismo electoral, sino que tiene una connotación y un impacto más profundos y más preocupantes, que rayan la pasividad en el ejercicio de la democracia y, consecuentemente, de las elecciones. Por ello, en este trabajo planteo la cuestión acerca de ¿cuál es el mejor método o instrumento para poder erradicar o al menos disminuir la pasividad democrática y electoral en México?, para lo cual propongo una postura iusnaturalista que es viable para sancionar y, eventualmente, erradicar esa pasividad, misma que considera sustancialmente al Juicio Democrático en sentido amplio.

En esa tesitura, el derecho natural es un gran aliado para ayudar a la democracia a superar sus problemas y a consolidarse, por lo que algunas categorías como la prudencia, la templanza, la justicia y la paz son necesarias para darle sustento conceptual a la premisa aquí planteada, que se traduce, durante su aplicación práctica, en un instrumento de carácter social que debe servir para erradicar esa pasividad democrática. Así, lo justo es que el incumplimiento de una norma destinada a la producción de la paz (o de cualquiera otra de las finalidades de la democracia) sea sancionado; para llegar a la anterior conclusión se hace necesario transitar por diversos conceptos que son fundamentales en el iusnaturalismo y que de una manera u otra soportan la idea de la justicia en cuanto al ejercicio de la democracia.

Contrastando con lo anterior existe la postura del iuspositivismo, por la cual se estructuran las normas jurídicas como producto de la actividad de los órganos del estado (el legislativo, específicamente) y se codifican en

Nacional (MORENA) obtuvo más del 53\% de la votación para su candidato a la presidencia de la república, con una importante influencia en los demás cargos de elección popular a nivel federal e incluso en las entidades federativas (INE, 2018).

${ }^{3}$ Traducido a dinero, las elecciones han sido cada vez más costosas debido al abstencionismo, por ejemplo, el presupuesto para la elección presidencial del año 2006 fue de 2,435 millones de pesos, la de 2012 de 4,173 millones y la de 2018 7,144 millones (cifras aproximadas), además de que existe un gasto de 2.9 millones de pesos destinado a crear conciencia en la ciudadanía y explicarle la 
cuerpos normativos que al ponerse en vigencia tienen aplicación en un espacio y tiempo determinados. Esa estructura normativa obliga a los destinatarios de esta a respetar y acatar lo establecido en las mismas, en virtud de la validez que le otorgan los procesos y los órganos que intervienen en ella. Una Constitución es indispensable en este proceso de creación de normas jurídicas, ya que les da validez a las normas creadas bajo los procesos por ella ordenados y por los órganos por ella creados para tal efecto. Esas normas pueden ordenar, prohibir o permitir conductas, con la posibilidad de que tal mandato no sea obedecido. Así, uno de los elementos que contiene la norma jurídica correctamente estructurada es la sanción para el caso de que los destinatarios de esta no la obedezcan, de tal manera que el iuspositivismo, en una de sus últimas consecuencias, indica que debe haber sanción para el caso en el que las conductas ordenadas sean omitidas. Una de las conductas ordenadas por la Constitución y las leyes mexicanas es el voto como uno de los instrumentos de la democracia, pero no es lo único, ya que la forma de gobierno democrática constriñe a los ciudadanos a que todo su actuar sea acorde con los principios, valores y, en general, actitudes democráticas; de esta manera, desde el momento en el que los ciudadanos omiten la conducta ordenada consistente en actuar democráticamente (aunado a la conducta específica de votar) se debe aplicar una sanción iuspositivista (en caso de haberla) pero también otra bajo la consideración de la justicia que auspicia el iusnaturalismo.

\section{ALGUNOS FUNDAMENTOS IUSNATURALISTAS PARA LA DEMOCRACIA.}

La teoría de la democracia implica al poder público y todo lo que ello conlleva, por ejemplo, la forma de obtenerlo, de conservarlo y, eventualmente, de transmitirlo, y ese poder implica una capacidad de mando que pueden ejercer aquellos que lo detentan por virtud de una cesión (ya sea temporal o de otra índole) del mismo. En las teorías clásicas que sustentan al derecho desde el punto de vista de su fundamento natural se encuentran varias posturas que son importantes para la comprensión de la democracia, mismas que se pueden ver en el pensamiento y reflexión de varios filósofos. Por tal razón, una de las primeras preguntas acerca del poder es la relacionada con el mando y su fuente. Así, Platón se cuestionó si el mando incumbe a la razón o no, ya que consideraba que en la razón reside la prudencia y ésta a su vez ejerce "inspección sobre la totalidad del alma”, y, en contraposición a esto, se pregunta si “no corresponde a la cólera obedecer y secundarla”; esas dos partes (la razón y la prudencia) ejerciendo su función de vigilar al poder de mando y a la cólera, regirán " ... el apetito sensitivo que ocupa la mayor parte de nuestra alma, que es insaciable por naturaleza ..." (Platón, 2001). De ahí que la razón y la prudencia sean dos elementos que deben tener una indiscutible influencia en las cuestiones de poder (o de

importancia de su participación; (Vanguardia.mx, 2018). 
mando, tal como lo conceptualiza el filósofo).

Posteriormente, en ese entramado de razón y prudencia como los elementos controladores del mando y de la cólera, se tiene como producto final a la justicia, y dichos efectos no llegan hasta los actos externos del hombre exclusivamente, sino que "... regula lo interior del mismo, no permitiendo que ninguna parte de su alma haga otra cosa que aquello que le es propio, y prohibiéndoles que recíprocamente se usurpen sus respectivas funciones ..." (Platón, 2001), es decir, la justicia significa que las partes del alma (entiéndase razón) no hagan otra cosa diferente (no tomen decisiones diferentes) a aquello que le es propio (lo correcto). En este punto, lo que le es propio o lo "correcto" es aquello que no atenta contra las demás personas, que respeta su integridad física y mental pero también su integridad social. ${ }^{4}$ Por eso, es importante que las funciones de cada cosa, de cada aspecto, sean las que efectivamente se realicen y no otras, de lo contrario estaríamos ante lo que el filósofo considera como "usurpación", lo cual no es otra cosa que una distorsión de los fines para los cuales fue creada una cosa, por ejemplo, el hombre:

"Quiere que el hombre, después de haber señalado debidamente a cada cual las funciones que propiamente le incumben ( ... quiere que entonces comience a obrar el hombre, ya se proponga acumular riquezas, ya cuidarse de su propio cuerpo, ya acogerse a la vida privada, ya intervenir en los asuntos públicos; que en todas esas circunstancias dé el hombre acción justa y hermosa a toda acción que haga nacer y mantenga en él ese hermoso orden..." (Platón, 2001).

El respeto a lo anterior es la base de la justicia. La observancia de todo eso conlleva una acción congruente con el actor, que es un elemento de la naturaleza con capacidad de raciocinio, que junto a la acción como elemento que ejecuta ese otro elemento de la naturaleza que goza de la capacidad de raciocinio (actor), son el binomio que, congruentes uno con el otro, no dan cabida a una calificación de “usurpación” en sus conductas. Por el contrario, una incongruencia en lo anterior permite, con toda justificación, una calificación de "usurpación" por no corresponder la acción con la naturaleza o con la función o finalidad del actor, lo que trae como consecuencia una injusticia o una acción injusta: “ ... y que, por lo contrario, llame acción injusta a la que destruya en él ese orden, e ignorancia a la opinión que presiden semejantes acciones ..." (Platón, 2001). De ahí se aproxima el filósofo a examinar lo que es la injusticia bajo las siguientes preguntas:

"¿Es acaso otra cosa que una sedición entre las partes del alma, que se dirigen a aquello que no es de su incumbencia, usurpando ajeno oficio, una sublevación de una parte contra el todo por abrogarse una autoridad que no le pertenece, porque está naturalmente hecha para obedecer a aquello que está hecho para mandar? De ahí, diremos, de ese desorden y de esa perturbación nacen la injusticia y la intemperancia. La cobardía y la ignorancia. En una palabra, todos los vicios..." (Platón, 2001).

La injusticia se da cuando las partes del alma (las decisiones de la razón) se dirigen a aquello que no es de

\footnotetext{
${ }^{4}$ Es decir, su relación derivada de toda una estructura social en la que se encuentra inmerso desde el momento de nacer y que suscribe por medio de un contrato o pacto de tipo social por el que se obliga a una serie de cargas y adquiere también una serie de derechos.
} 
su incumbencia, lo cual significa que la razón debe producir actos acordes con la propia naturaleza de la persona. Si la razón y su producto se dirigen a un fin distinto al que debe estar orientado el sujeto, es decir, si la razón se ejecuta "usurpando ajeno oficio", entonces surge la injusticia y la intemperancia. ${ }^{5}$ Ahora bien, las leyes producidas por el Estado deben ser acordes a la forma del propio Estado y a las finalidades de este, con lo que se estaría haciendo congruente con su esencia. Si el Estado es democrático, entonces las leyes que el propio Estado emita deben ser acordes con los principios de la democracia, pero no solamente eso, sino que también las leyes que regulen los procesos democráticos (no solamente aquellos referidos a las elecciones, sino todos los demás que estén previstos), deben tener una regulación acorde con esos principios. Lo anterior significa que la actividad del legislador debe estar dirigida a la formación de leyes que tengan esas características, y no debe crear leyes contradictorias e incongruentes con los principios que se establecen en los principios estatales que constitucional o fundamentalmente están establecidos.

Aquí cabe la siguiente pregunta: ¿cómo debe el legislador formar las leyes? y la respuesta surge por vía del siguiente cuestionamiento: “¿No es consultando al mayor bien, como todo legislador debe formar sus leyes?" (Platón, 1998), se contesta diciendo que el mayor bien para un Estado no es la guerra ni la sedición, sino la paz y la buena inteligencia entre los ciudadanos y concluye: “... la razón preside a todas estas pasiones, y ella declara lo que tienen de bueno y de malo; y cuando el juicio de la razón se convierte en una decisión general para un Estado, entonces toma el nombre de ley..." (Platón, 1998). En ese sentido, el filósofo llama “justo" a lo que produce y protege a la felicidad y lo que ella conlleva en un medio político y social, ya que la ley ordena (o debe ordenar) actuar como valiente y como temperante y, en síntesis, ordena unas cosas (que son acordes con la naturaleza humana y, por tanto, justas) y prohíbe otras (contrarias a la misma y, por tanto, injustas).

¿Cómo es que la ley pertenece al género de la razón? Es una cuestión bajo la cual se pretende buscar la justificación iusnaturalista que sustenta a la razón como la principal fuente de lo jurídico. La reflexión filosófica que da contestación a esto nos la proporciona Tomás de Aquino al aseverar que “... es propio de la razón ordenar a un fin, y esto ( ... ) es el primer principio de los actos, y en todo género de cosas, así como por ejemplo la unidad en el género de los números y el primer movimiento en el orden del movimiento. De ahí se sigue que la ley es algo que pertenece a la razón ..." (Tomás de Aquino, 2004). Como ordenadora de los fines y como principio de los actos humanos, y en virtud de que la ley tiene como finalidad regular esos fines humanos y también sus actos (su conducta), la razón es su fuente; además de que la estructura conceptual de la ley (hipótesis normativa incluida) es un constructo que solamente puede ser producido por el raciocinio humano. El fin último de las cosas y, desde

\footnotetext{
${ }^{5}$ Lo que es una falta de templanza, un atentado a la moderación, a la sobriedad y a la continencia. En religión se trata de una de las cuatro virtudes cardinales del hombre (junto con la prudencia, la justicia y la fortaleza), y consiste en moderar, con base en la razón, los apetitos y los sentidos para evitar su exceso y, por consecuencia, impedir la corrupción del hombre por sus actos.
} 
luego, del ser humano y su pensamiento incluido, es una de las mayores preocupaciones que han tenido los filósofos y que ha dado pauta a reflexiones profundas, al grado de que se ha considerado que el fin último de la vida es “... la felicidad o gozo ( ... ) Luego es necesario que la ley ante todo se dirija al orden de la felicidad ...” (Tomás de Aquino, 2004). Por tanto, ese trayecto epistémico que intenta explicar los fines últimos de la ley es el que nos puede ayudar a determinar otro tipo de fines, por ejemplo, si el fin último (o uno de ellos) de un Estado es la democracia; luego entonces, es necesario que la ley del Estado ante todo se dirija al orden de esa democracia, de sus principios y de sus procesos. Por ello, el voto pasivo y el activo deben estar ordenados y reglamentados por la ley estatal, toda vez que ese Estado y su gobierno tiene forma democrática. Asimismo:

"... La ley, ante todo y principalmente, mira al bien común. Y al ordenar todo al bien común es propio o de todo el pueblo o de quien toma la representación del pueblo. Y por tanto el hacer la ley es propio o de todo el pueblo o de la persona pública que tiene a su cuidado la dirección de toda la comunidad. Porque en todas las cosas quien debe ordenarlas a un fin es aquel a quien pertenece dicho fin ..." (Tomás de Aquino, 2004).

Si la democracia pertenece al pueblo como un fin en sí misma, luego entonces la democracia debe ser ordenada por el propio pueblo aún a costa de otros miembros del pueblo que con su conducta no ayuden a que la democracia y sus principios se concreticen o que la obstaculizan.

Ahora bien, bajo toda esta conceptualización está inmersa la idea de la virtud respecto a ciertos aspectos como el apetito irascible y concupiscible, que consiste en que "... se sometan bien a la razón ( ... es virtud en un súbdito el saberse someter bien al gobierno del soberano ( ... pues a este fin se ordena cualquier ley: a que sea obedecida por los súbditos ..." (Tomás de Aquino, 2004), y también a ese fin se ordena la democracia: a que sea practicada por los ciudadanos siempre que la ley sea dirigida a la virtud: "Y así queda manifiesto que es propio de la ley el inducir a los súbditos a la propia virtud. Y siendo la virtud lo que hace bueno a quien la posee, se sigue que es un efecto propio de la ley el hacer buenos a aquellos para quienes se da, sea simplemente, o según algunos aspectos ..." (Tomás de Aquino, 2004). También queda de manifiesto que es propio de la democracia el inducir a los ciudadanos a la práctica de esta y de sus valores y principios, es decir, a la libertad de expresión, de reunión, de elección, y de todos aquellos derechos inherentes al ciudadano como un ente político inmerso en un medio estatal.

Por otro lado, otro filósofo del derecho natural asevera lo siguiente: “... donde no hubiere verdadera justicia tampoco podrá haber derecho, lo que se hace según derecho se hace justamente; pero lo que se hace injustamente no puede hacerse con derecho. Porque no se deben llamar o tener por derecho las leyes injustas de los hombres ..." (San Agustín, 2004). De ahí que, donde no hubiere verdadero respeto y ejercicio de la libertad de expresión, de reunión, de deliberación (valores y principios básicos de la democracia), no podrá haber democracia, ya que aquello que se hace con libertad e igualdad se hace democráticamente, pero aquello que se hace antidemocráticamente no puede decirse que se hizo libre o equitativamente (ni igualitariamente). 
Consecuentemente, la omisión o deficiente regulación legal respecto de la democracia y todo lo que ella conlleva, se vuelve una circunstancia injusta, ya que al no poder prever los casos relativos a la conducta democrática (por no existir una normatividad) el surgimiento de alguno de ellos (hipotético pero potencialmente posible) podría quedarse sin el debido tratamiento legal y jurídico, resultando en una circunstancia por demás injusta para el sujeto (o incluso para la institución) involucrado en la misma.

En otra clásica conceptualización tenemos que "Las leyes en su significación más extensa, no son más que las relaciones naturales derivadas de la naturaleza de las cosas; y en este sentido, todos los seres tienen sus leyes: la divinidad tiene sus leyes, el mundo material tiene sus leyes, los animales tienen sus leyes, el hombre tiene sus leyes ..." (Montesquieu, 2005). Si consideramos como una "naturaleza" a la democracia y como un derivado "natural" todo lo que a ella implique, entonces las acciones, los actos, las instituciones, así como los procesos que están destinados a la realización de la democracia, deben establecerse a través de leyes que signifiquen las relaciones de la democracia con sus derivados naturales.

Así, la democracia constituye toda una serie de pactos y relaciones derivados de la conducta de las personas y también de su naturaleza social. El ser humano es social por naturaleza y, como consecuencia de esa característica social, tiene una natural y potente inclinación hacia los actos y conductas en los que se encuentra necesariamente involucrado otro ser humano. La característica gubernamental de un Estado está dada precisamente por eso: por la decisión en cuanto a la posesión del poder estatal que significa el ejercicio del binomio mandato-mandante, en una necesaria relación entre personas (ciudadanos) bajo un acuerdo o pacto: "Por el pacto social hemos dado existencia y vida al cuerpo político: tratase ahora de darle movimiento y voluntad por medio de la ley; pues el acto primitivo por el cual este cuerpo se forma y se une, no determina nada de lo que debe hacer para asegurar su conservación ..." (Rousseau, 2004). Todo ello debe necesariamente tomar la forma legal, es decir, la estructura en el lenguaje codificado que contiene un cúmulo de conceptos e ideas que establecen los derechos y obligaciones democráticos aunado a las sanciones para el caso de incumplimiento y de la institucionalización de los órganos encargados de ello por medio de una serie de instrumentos o procedimientos también previamente regulados en la legislación, pero inicialmente en la Constitución, donde se establece la obligación de votar, es decir, la premisa fundamental que evita el abstencionismo electoral y/o la pasividad democrática.

\section{LA OBLIGACIÓN CONSTITUCIONAL DE VOTAR.}


De acuerdo con la Constitución Política de los Estados Unidos Mexicanos, votar en las elecciones populares es un derecho del ciudadano, pero también es una obligación. ${ }^{6}$ Sin embargo, la interpretación que se le debe dar a esto no debe quedar en la simple conclusión de que ese precepto es una antinomia, ya que contiene simultáneamente un mandato y una permisión, sino que se debe interpretar sistemáticamente considerando la forma de gobierno que por mandato constitucional se tiene en México, es decir, democrática. Si consideramos lo anterior, entonces se puede válidamente concluir que la permisión consistente en "votar es un derecho" pierde fuerza normativa para inclinar el mandato con una mayor carga hacia la obligación de votar. Lo anterior es así ya que, si se considerara que el voto es un derecho, con las inherentes posibilidades de ejercerlo o no (ya que un derecho convierte una conducta en potestativa), se estaría infringiendo la forma de gobierno democrática, llegando incluso a un extremo en el que muchos -o incluso todos - los ciudadanos tomaran la decisión constitucional y legalmente permitida de no ejercer el sufragio, con las consecuencias obvias que esto traería. Por ello, es de suma importancia interpretar de esta manera ese mandato constitucional en un sentido obligatorio para que los ciudadanos ejerzan el voto.

Un régimen democrático se caracteriza por la existencia de normas y reglas que delimitan de manera concreta y sin confusiones, los instrumentos de participación ciudadana (como el de votar), así como los alcances de esos instrumentos. Es decir, las leyes en un Estado democrático establecen instrumentos de participación ciudadana y sus alcances, con lo que queda completada la regulación respectiva, además de que establece las instituciones y los órganos de gobierno que son los encargados de vigilar su aplicación y cumplimiento. Estos deben ser los mínimos aceptables para considerar que un Estado se encuentra bajo un régimen de democracia participativa, en otras palabras: una democracia de calidad (o, en un extremo, una verdadera democracia). En otro sentido absurdo tendríamos un régimen democrático formal (de papel, como dijera Lassalle cuando se refirió a la Constitución "formal"), en el que (intencionalmente o no) se obstaculizan los mecanismos de participación de los ciudadanos en los asuntos de Estado o, en un extremo, que ni siquiera estuvieran legislados esos mecanismos. En una definición de "democracia de calidad" nos encontramos con "... aquella que presenta una estructura institucional estable que hace posible la libertad e igualdad de los ciudadanos mediante el funcionamiento legítimo y correcto de sus instituciones y mecanismos" (Morlino, 2003), y precisamente son esos mecanismos por los que se puede acceder a la esencia de la democracia (es decir, la participación), los que le dan un sentido congruente a esa esencia: un régimen que prevé la participación de los ciudadanos para la conformación del gobierno y de las instituciones estatales en el que ineludiblemente se incluyen las reglas para que eso sea posible, lo cual hace que el régimen democrático que cumple con esto sea, además, de calidad.

\footnotetext{
${ }^{6}$ Artículos 35, párrafo primero y 36, párrafo tercero.
} 
Por ello, la doctrina ha generado una clasificación de los aspectos mínimos que deben satisfacerse para que un Estado sea considerado como democrático (Dahl, 1998):

1. El gobierno se encuentra efectivamente bajo la operación de funcionarios que han sido electos.

2. Los procesos electorales son libres, imparciales y frecuentes.

3. Hay una verdadera liberta de expresión.

4. La ciudadanía tiene una real y efectiva posibilidad de acceder a fuentes alternativas de información.

5. Existe una verdadera libertad de organización y de reunión.

6. La ciudadanía forma un ente inclusivo.

Como se puede ver, todos esos aspectos mínimos están dirigidos a las consecuencias de practicar o de aplicar la democracia y sus características o lineamientos (incluso más aún: sus valores y principios). Además de los anteriores, para que haya una real consolidación democrática, la doctrina ha considerado que se deben satisfacer los siguientes aspectos (Linz, 1996):

1. No pueden coexistir instituciones que gozan de una verdadera estructura democrática con aquellas que no lo son.

2. La democracia se convierte en la única ruta a recorrer cuando ningún grupo organizado se opone seriamente al régimen.

3. El impero de la ley es un aspecto fundamental y el estado de derecho impera en la solución de controversias sociales.

4. La mayoría de la sociedad apoya la idea de que los procesos e instituciones democráticas son la forma adecuada de acceder a los derechos políticos, sociales y económicos.

5. Hay una abundante participación de diversos actores con relación a la formulación, implementación y evaluación de políticas.

Los aspectos mencionados abonan significativamente a la consolidación de la democracia y de sus procesos o mecanismos para hacerla efectiva, es por lo que no se puede considerar a la democracia solamente como un derecho con la cualidad de potestativo, ya que se podría llegar al extremo de no poder conseguir esos aspectos mínimos que han sido considerados por la doctrina como los indispensables para que podamos calificar de "democrático" a un Estado o a una sociedad. De ahí que, no obstante que la Constitución considera al voto activo bajo el doble aspecto de derecho y obligación, la interpretación adecuada que se le debe dar es de obligación (o tal vez más correctamente de un "deber"), así no se correría el riesgo de que ocurriera la pasividad

\footnotetext{
${ }^{7}$ Riesgo que de hecho ya está ocurriendo, solamente basta con revisar las estadísticas del abstencionismo electoral y otras que nos indican la poca participación de la ciudadanía en otros menesteres estatales, por ejemplo, la solicitud de información por vía de transparencia o la exigencia del cumplimiento de las promesas de campaña con la consecuente revocación de mandatos o, incluso,
} 
electoral bajo la justificación de que se trata de un derecho que, como tal, es solamente potestativo.

\section{A DEMOCRACIA CONSTITUCIONAL Y LA PASIVIDAD ELECTORAL.}

En México, la Constitución Política contiene en varios de sus preceptos, el concepto de democracia, ${ }^{8}$ ya que al organizar y estructurar al Estado es imperativo que se mencione ese concepto por medio del cual se hace posible la formación e integración de los órganos de gobierno (estructura) por los propios ciudadanos a través de los diversos instrumentos que contiene (como los electorales). Con esto se logra cierta congruencia en el contenido de la Constitución al establecer el parámetro democrático en otros ámbitos de la vida estatal. La doctrina ha considerado que la democracia como ideología debe estar continuamente remodelándose de acuerdo con los movimientos y transformaciones de la propia sociedad (la cual es cambiante por esencia); sin embargo, el principio de la mayoría es un aspecto que debe prevalecer:

...la democracia debe ser suficientemente flexible, para adecuarse a las distintas realidades sociales, en el tiempo y en el espacio. No puede servir la misma fórmula de gobierno para un país con un nivel cultural medio de cierta altura y otro de nivel bajo, ni podría ser igual en la Grecia de las ciudades que en las complejas ciudades del presente; y sin embargo, debe permanecer algo, que es lo que constituye la esencia y que no puede descartarse sin destruir a la institución democrática; ese algo es el principio de que la democracia reposa en el gobierno de las mayorías ..." (Seara Vázquez, 1978:23).

Dice el autor que el principio de la mayoría es indispensable para la existencia de la democracia, al punto en el que, si se descartara tal principio se estaría destruyendo la institución democrática. Se trata del gobierno de las mayorías, de donde surge el principio democrático de la mayoría por el cual las decisiones son tomadas por el mayor número de las personas facultadas por la ley para tomar las decisiones; es la base decisional sobre la que descansan muchos de los países cuyo régimen es el democrático. Sin embargo, no es el único fundamento de la democracia, ya que también podemos considerar a la libertad y a la igualdad, y hay autores que consideran que esos principios entrelazados pueden dar la mejor descripción de lo que es la democracia ya que conjunta algunos elementos de tipo político con categorías sociales e, incluso, morales, que tienen relación directa con la actuación del ciudadano (Touraine, 2004). La democracia es un instrumento de toma de decisiones (las cuales pueden tomarse de manera directa o por medio de representantes), por lo que se ha definido como un arreglo

\footnotetext{
la iniciativa de ley o la participación en las consultas populares.

${ }^{8}$ Específicamente en los artículos 30, fracción II, inciso a) (referido a la educación), 60, apartado B, fracción V (referido a la diversidad y pluralidad de ideas y opiniones), 25 (referido a la rectoría del Estado en materia de desarrollo nacional), 26 (referido a la organización estatal de un sistema de planeación), 27 (referido a la elección del Comisario Ejidal o de bienes comunales), 40 (referido a la voluntad del pueblo mexicano para constituirse en una República), 41, fracción I (referido a la finalidad de los partidos políticos de promover la participación del pueblo), 115 (referido a la forma de gobierno que los estados adoptarán en su interior). ${ }^{9}$ Que también son lemas adoptados por la revolución francesa ("Libertad, Igualdad y Fraternidad") como uno de los movimientos políticos y sociales de la historia mundial por el que se configuraron nuevos paradigmas estatales y gubernamentales.
} 
institucional para arribar a decisiones políticas y en el que las personas, en su carácter de ciudadanos, pueden participar por medio de una contienda competitiva por el voto de la gente (Schumpeter, 1976). Incluso hay quien considera otros elementos importantes (indispensables para la felicidad de las personas), como la libertad de expresión:

La libertad de expresión nos permite realizarnos como personas, al propiciar nuestro crecimiento intelectual y moral. Al estar expuestos a una diversidad de ideas, pensamientos, noticias e informaciones, podemos ir forjando nuestra propia personalidad y delimitando los ideales para guiar nuestra existencia. La libertad de expresión nos permite ser individuos más maduros y reflexivos, con lo cual nos beneficiamos nosotros, pero también beneficiamos a la sociedad donde vivimos ..." (Carbonell, 2012:80).

La posibilidad de expresarse libremente es también la posibilidad de hacer democracia. El hecho de que un ciudadano pueda expresar lo que siente (siempre que se cumplan los requisitos legales que, generalmente, hacen referencia al respeto a los derechos de los demás), es sinónimo de un ciudadano que vive en democracia, que se somete a los principios y reglas de la democracia y que, en suma, ejerce la democracia. Así, la libertad de expresión significa también la posibilidad de que el ciudadano acuda a las casillas electorales el día de la elección y emita un sufragio para expresar su preferencia respecto a quién le gustaría que ocupara un cargo público. Un impedimento (material o legal, directo o indirecto) para realizar lo anterior significaría una limitación a la libertad de expresión en detrimento de la democracia y su debido ejercicio. Sin embargo, en un Estado en el que hay diversas normas constitucionales y jurídicas que permiten la libre expresión y que regulan la posibilidad de ejercer el sufragio, es un Estado cuyo sistema jurídico-democrático (más que jurídico-electoral) está orientado al ejercicio de la democracia específicamente representativa:

En este sentido, se parte del criterio de que, en un sistema de democracia representativa, la participación de los ciudadanos por vías legalmente reconocidas es complementaria a la idea de representación, refuerza los principios y valores democráticos, además de que evita que las demandas y puntos de vista de la ciudadanía se difundan y se pierdan valiosas contribuciones de la sociedad al ámbito público... (Balbuena Cisneros, 2010:61).

En eso radica la importancia de la libertad de expresión: la ciudadanía tiene la posibilidad (en un extremo puede incluso considerarse como obligación) de expresar sus ideas respecto a la vida estatal, lo cual también representa la posibilidad de recabar los pensamientos, ideas, soluciones, etc., de las personas que están involucradas en la problemática social y que, por ende, pueden potencialmente proponer alguna solución a la misma, derivada de su experiencia personal. Por ello, la democracia no debe considerarse solamente desde el punto de vista de su definición básica, es decir, aquella que solamente refiere al gobierno del pueblo y a los instrumentos electorales de renovación de cargos públicos, sino que se debe invocar una conceptualización más sofisticada que refiera a la participación del ciudadano, específicamente a la democracia participativa, término que ya se ha usado por la doctrina: "... la democracia participativa se perfila como alternativa que promueve la ampliación de los derechos de los ciudadanos, a través de la participación proactiva en el proceso de consolidación 
democrática para la crisis de confianza institucional ..." (Bin, 2005). De ahí que la democracia participativa se erija en un concepto contrario a la pasividad democrática y al abstencionismo electoral, ya que implica la conducta activa destinada al involucramiento en los asuntos del Estado y de la sociedad en general, desarrollada por los ciudadanos y auspiciada por las leyes estatales.

Ahora bien, la pasividad democrática (como género del abstencionismo electoral y de otros fenómenos de la democracia), implica una falta de acción o de actuación en donde algunos ciudadanos permanecen al margen de una acción y, por consecuencia, dejan obrar a otros ciudadanos, lo que significa que solamente unos cuantos son los que toman las decisiones de carácter público con los consecuentes problemas de legitimidad que esto acarrea. De hecho, los términos "pasividad" y "democracia" son antagónicos, ya que ésta última implica necesariamente una actividad proactiva, una participación pronta, diligente y ágil en los asuntos públicos y estatales. Por ello, los niveles de abstencionismo en México son preocupantes al punto en el que se ha provocado (más allá de la crisis de legitimidad) una "crisis de confianza institucional" que es consecuencia de toda una serie de fenómenos ocurridos a lo largo de la historia democrática reciente en México y en la que a pesar de la formalidad legal (que, aunque incipiente, ya representaba una regulación digna de aplicarse) no había una aplicación real de lo preceptuado respecto a la democracia y su ejercicio. Incluso actualmente tenemos todo un sistema democrático-electoral que representa la evolución de la regulación jurídica (constitucional y legal), pero que no es suficiente para atacar de raíz esa pasividad democrática y electoral, por lo que se hace necesario implementar otras soluciones alternativas que deben aplicarse no en sustitución de ese sistema, sino además o por encima de él, con el objetivo de complementarlo y reforzarlo para concretar cada vez más la democracia, no solamente como estructura jurídica o régimen político, sino como sistema de vida. ${ }^{10}$ De esta manera, propongo una alternativa para erradicar esa pasividad democrática y electoral en México que debe estar fincada en una tesis iusnaturalista y sancionadora: el juicio democrático.

\section{EL JUICIO DEMOCRÁTICO CONTRA LA PASIVIDAD ELECTORAL.}

El juicio democrático es producto de una postura iusnaturalista, ya que se sostiene gracias a esos postulados del derecho natural analizados previamente (la prudencia, la razón, la templanza y la justicia), y también por sus contenidos conceptuales y por el efecto que tienen en su aplicación práctica, por lo que

\footnotetext{
${ }^{10}$ La Constitución Política de los Estados Unidos Mexicanos, en su artículo 3o, fracción II, inciso a), dice que el criterio orientador de la educación será democrático "... considerando a la democracia no solamente como una estructura juridica y un régimen político, sino como un sistema de vida fundado en el constante mejoramiento económico, social y cultural del pueblo”.
} 
representan los elementos esenciales del contenido de ese juicio. Por otro lado, el funcionamiento estatal y el Estado de Derecho son dos de los elementos que se regulan bajo los estándares de la democracia y sus principios y que regulan también la organización y funcionamiento de las instituciones. Lo anterior es de suma importancia, ya que se puede sujetar la actividad estatal a la Constitución y a las normas válidas ${ }^{11}$ que garantizan el funcionamiento responsable y controlado de los órganos de poder, así como el ejercicio de la autoridad de acuerdo con disposiciones no retroactivas (perjudiciales) y la observancia y respeto de los derechos individuales, sociales, culturales y políticos (Valadés, 2004).

Asimismo, un elemento indispensable para el funcionamiento de los estados es el relativo a la sociedad civil, factor de suma importancia sin el cual no podría existir una verdadera estructura estatal ni democrática; en efecto, las demandas sociales que desembocan en la vigilancia del gobierno y sus acciones se caracteriza por ser el espacio organizado de la vida social, voluntario, espontáneo y autónomo en el que también converge la sociedad civil como la categoría general que involucra a los ciudadanos, interactuando colectivamente en la cosa pública al expresar sus opiniones e intercambiar información para conocimiento de las acciones del gobierno y de las instituciones, por lo que se considera que la sociedad civil está posicionada entre lo privado y el Estado (Coppedge, 2001). Así, constituye un enlace entre esos dos entes: el aparato estatal y los ciudadanos individual o colectivamente considerados, de donde surge el concepto de democracia participativa como una concepción refinada de la democracia en la que la participación de los ciudadanos es indispensable para el funcionamiento de un Estado. La democracia participativa tiene como uno de sus primeros y más deseables efectos la promoción de la ampliación de los derechos ciudadanos. Esto contrasta con la pasividad (e incluso apatía) de las acciones ciudadanas (ya sean individuales o colectivas), por lo que urge que cada ciudadano sea un portador de la palabra crítica, un evaluador de las acciones antidemocráticas, un vigilante de las conductas ilegales y un sancionador de todo aquello que signifique una vulneración a los principios democráticos.

Además de la democracia participativa existe otro adjetivo que está muy relacionado con la idea de participación y que también urge implementar, se trata de lo que algunos autores han llamado la "democracia de opinión" (Pavarini, 2006), que no es otra cosa más que un derivado de la libertad de expresión y del aspecto participativo, ya que con la libertad de expresión se tiene la posibilidad de dar a conocer las ideas personales sobre algún aspecto de la vida pública o de Estado (siempre que se respeten los límites legales y los derechos de los demás). La democracia debe estar presente no solamente en la forma de gobierno o en el régimen político, sino también en la forma de vida, la cual debe ser acorde con esa libertad de expresión y con esa capacidad ciudadana de participación en los asuntos de Estado incluyendo la observación, vigilancia y, eventualmente, la sanción a las

\footnotetext{
${ }^{11}$ Entendiendo por validez el cumplimiento de los procedimientos ejecutados por los órganos formalmente establecidos.
} 
conductas que no sean propiamente democráticas o que infrinjan a la democracia o a sus postulados. Para lo anterior se requiere que las personas, los ciudadanos, sean individuos que ejercen la libertad de expresión y que pueden manifestar sus ideas y opiniones respecto a la actuación y conducta de las demás personas y/o ciudadanos, para vigilar, observar y, en caso de ser necesario, sancionar aquellas que sean en contra de la democracia. Lo anterior es así, ya que la deliberación de las ideas y opiniones en un ámbito democrático es indispensable para el desarrollo de los pueblos:

La noción de democracia deliberativa está enraizada en el ideal intuitivo de una asociación democrática en la que la justificación de los términos y condiciones de la asociación tienen lugar a través de la argumentación y del razonamiento público entre ciudadanos iguales. En tal orden los ciudadanos comparten el compromiso de resolver los problemas de elección colectiva mediante el razonamiento público y tienen sus instituciones básicas por legítimas en la medida en que éstas establecen un marco para la deliberación pública libre... (Habermas, 2005:381).

De acuerdo con lo anterior, la comunicación entre personas o seres iguales no es posible sin la argumentación, para lo cual se requiere forzosamente de una deliberación inherente al ejercicio democrático, es decir, no hay deliberación como una forma de discutir las ideas, de reflexionar las propuestas y de analizar los problemas, si no existe ejercicio argumentativo de los sujetos inmersos en la acción comunicativa ni de los sujetos involucrados en la problemática objeto de la discusión. Aquellos que ejecutan los actos necesarios para la deliberación y discusión de los asuntos de Estado son los que podrían realizar también el juicio democrático, ya que la deliberación y el resultado de la discusión y la contrastación de las ideas, así como la crítica y el análisis de esos asuntos, los puede colocar en la adecuada aptitud para sancionar las conductas que sean diferentes de lo que dictan los principios de la democracia. Es decir, los que deliberan pueden realizar un juicio democrático. Sin embargo, no es suficiente lo anterior, sino que es necesario también que la intención ciudadana de ser partícipe en los asuntos de Estado sea encauzada por vías institucionales para que tenga una mejor repercusión e impacto en la vida social, esto implica la existencia de diseños que tal vez no existan aún en la realidad mexicana o que, en caso de existir, es probable que no sean suficientes:

"El desarrollo y consolidación de una política deliberativa, la teoría del discurso los hace depender, no de una ciudadanía colectivamente capaz de acción, sino de la institucionalización de los correspondientes procedimientos y presupuestos comunicativos, así como de la interacción de deliberaciones institucionalizadas con instituciones públicas desarrolladas informalmente" (Habermas, 2005:374).

Esos procedimientos y presupuestos comunicativos requieren de garantía en la realización de la libertad de reunión, la cual está plasmada en la Constitución Política de los Estados Unidos Mexicanos ${ }^{12}$ y atiende a una de las principales y primeras actividades, incluso naturales, del ser humano, que es la posibilidad de que conviva con otros, y uno de los productos de esa convivencia es la discusión de ideas y de puntos de vista, la contrastación de

\footnotetext{
${ }^{12}$ El artículo 9 de la Constitución establece: "No se podrá coartar el derecho de asociarse o reunirse pacíficamente con cualquier
} vol.12, no. 01, Rio de Janeiro, 2019. pp.327-346 
posturas y, eventualmente, la toma de decisiones en un medio en el que se conocen las posturas de varias personas. Es así como surge la educación y la información (ambas tan necesarias para la democracia), y también se da el respeto y ejercicio de los principios y valores de la democracia. El producto de la reunión de seres humanos pensantes, críticos y participativos es la argumentación y el razonamiento público dado entre ciudadanos iguales:

La noción de democracia deliberativa está enraizada en el ideal intuitivo de una asociación democrática en la que la justificación de los términos y condiciones de la asociación tienen lugar a través de la argumentación y del razonamiento público entre ciudadanos iguales. En tal orden los ciudadanos comparten el compromiso de resolver los problemas de elección colectiva mediante el razonamiento público y tienen sus instituciones básicas por legítimas en la medida en que éstas establecen un marco para la deliberación pública libre... (Habermas, 2005:381).

El resultado es un proceso de entendimiento derivado de los procesos de la democracia, es decir, de la deliberación, discusión, crítica, análisis, etc, lo cual no es otra cosa más que la libertad de expresión desarrollada por los integrantes de una sociedad democrática cuya política está sujeta a revisión y reflexión en espacios públicos:

la teoría del discurso cuenta con la intersubjetividad de orden superior que representan los procesos de entendimiento que se efectúan a través de los procedimientos democráticos o en la red de comunicación de los espacios públicos políticos ... (Habermas, 2005:375).

Así, la democracia y su lado deliberativo adquieren importancia para las decisiones en cuanto a los asuntos públicos o estatales; por ello la participación y la expresión de la voluntad de los ciudadanos es un factor indispensable para la conformación de un gobierno estatal y, por ende, para la democracia. Derivado de lo anterior, el involucramiento del ciudadano en los asuntos públicos es de vital importancia para la democracia, se trata de la posibilidad de que el ciudadano vigile, supervise, cuestione, e incluso regule, la conducta de los gobernantes y en general de todos aquellos que detenten una parte del poder público y más que eso, la posibilidad de que los ciudadanos se inmiscuyan en la ideología de esos detentadores del poder público o de quienes pretendan asumir un cargo de elección popular y de ahí partir hacia la posibilidad de que conozcan y discutan la postura ideológica de otros ciudadanos en un acto de toma de decisiones para la elección de esos detentadores del poder público. Se trata de una ciudadanía regulando a la propia ciudadanía, no solamente a los gobernantes, lo cual constituye una especie de juicio democrático contra la pasividad democrática y electoral en México. No solamente es necesario conocer y cuestionar a cabalidad y de manera exhaustiva a la persona que pretende ser una figura pública o que ya lo es, sino que también es indispensable conocer y cuestionar a las personas que los van a elegir para ser figuras públicas, y en esto se ve implicada una situación en la que los ciudadanos pueden regular e influir en la decisión de otros ciudadanos para una mejor toma de decisiones. Desde luego que la abstención quedaría erradicada si toda la ciudadanía o una gran parte de ella ejecutara lo anterior, ya que el análisis y

objeto lícito; pero solamente los ciudadanos de la República podrán hacerlo para tomar parte en los asuntos políticos del país ...”. 
cuestionamiento lleva a la discusión de las ideas y de las posturas y, eventualmente, produce una participación cada vez más activa dependiendo del grado e intensidad con la que se analicen, cuestionen y critiquen las posturas, ideas e, incluso, conductas.

Los instrumentos institucionales con los que cuenta el ciudadano para allegarse del conocimiento mencionado y para estar en la posición de poder deliberar democráticamente, pueden ser el derecho de petición, el derecho a la información, los mecanismos de transparencia gubernamental, la posibilidad de asistir a las reuniones en las que los candidatos realizan sus campañas electorales, la consulta a los medios de comunicación y a los debates realizados entre candidatos o actores públicos. Con esto lo que se lograría que el ciudadano poseyera un mínimo de conocimiento sobre la situación pública que guardan los negocios de Estado y así poder emitir decisiones electorales o democráticas en general, más reflexionadas y, por consecuencia, libres. Pero no solamente eso, sino que además podría estar en la posibilidad de influir en otros ciudadanos para que de la misma manera ejerzan su derecho democrático y electoral de tomar decisiones de carácter público. El objetivo es la confrontación de ideas, planes y programas de gobierno o ciudadanos, pero también las ideas, sentimientos y propuestas de los aspirantes a los cargos públicos y de aquellos que los eligen, es decir, de otros electores.

La comunicación implica argumentación, razonamiento, discusión, etc., todo ello contenido en el concepto de deliberación como uno de los elementos indispensables de la democracia, además de que esa comunicación se debe dar sin intermediación ente los ciudadanos con la posibilidad de aclarar y/o demostrar o fundamentar los argumentos, ideologías, posturas, posiciones, acusaciones, etc. y esto produce una mayor circulación de la información y de las diferentes posturas o maneras de resolver un problema o de tomar una decisión, ya sea (como se dijo) sobre quiénes habrán de representarnos y ejercer el poder público delegado o sobre aquellos que toman también esas decisiones (es decir, otros ciudadanos).

Todo lo anterior implica que el ciudadano realice un juicio democrático por medio del cual valore y califique las ideas y posicionamientos de los demás miembros de la población, ya sean políticamente activos o no, con la finalidad de que se logre una mejor comprensión de los temas de Estado y se tomen las mejores decisiones. Esto es el resultado de la discusión, análisis y crítica que lleva a la observancia y vigilancia de las ideas de las demás personas (incluidos gobernantes o servidores públicos), la posibilidad de que las decisiones sean el verdadero resultado de la reflexión deliberativa y colectiva, además de que durante el proceso para cumplir con lo anterior ya se está satisfaciendo también otro aspecto de suma importancia: la participación. Así, la deliberación y la participación cuyo producto es la comprensión de las decisiones, no son otra cosa más que un juicio democrático que, además de sancionar las ideas no democráticas o alejadas de los principios de la democracia, sancionan también la conducta antidemocrática, por ejemplo, la abstención electoral, que es también una especie de pasividad democrática. 


\section{CONCLUSIONES.}

Primera. La razón y la prudencia tienen una importante influencia en el poder y también en el mando que es inherente al poder, ya que lo vigilan; el producto final de esto es la justicia, ya que regula los actos externos del hombre pero también su interior: la justicia significa que la razón no tome decisiones diferentes a lo que le es propio, es decir, a lo correcto, que es aquello que no atenta contra las demás personas y que respeta su integridad física, mental y social. La congruencia entre el actor y su acción impide la usurpación en la conducta. La injusticia se da cuando las decisiones de la razón se dirigen a aquello que no es de su incumbencia, luego entonces, el legislador debe crear leyes con esas características, es decir, congruentes con los principios constitucionales y legales. Si la democracia es el fin último del Estado (entre otros) entonces la ley estatal debe ordenar esa democracia. Es propio de la democracia inducir a los ciudadanos a su práctica (valores y principios inclusive). La omisión o deficiente regulación democrática (valores y principios incluidos) es una circunstancia injusta.

Segunda. El voto debe ser considerado solamente como obligación, ya que si también se considera como derecho se tendría que considerar como una conducta potestativa con la consecuente posibilidad de no ejercerlo, lo cual es contrario a la esencia de un Estado democrático. Lo esencial en la democracia es prever la participación de los ciudadanos para construir un gobierno y sostener las instituciones relacionadas con sus valores y principios; esto conlleva la existencia de un régimen democrático de calidad.

Tercera. El impedimento material o legal, ya sea de manera directa o indirecta, de ejercer el sufragio significa una limitación a la libertad de expresión y un perjuicio a la democracia junto con sus principios y valores. Por el contrario, el ejercicio de la libertad de expresión implica una conducta apegada a los estándares de la democracia y, llevada a un extremo deseable, le da soporte a la participación ciudadana, por lo que la democracia participativa se erige en un concepto antagónico a la pasividad democrática y al abstencionismo electoral.

Cuarta. El juico democrático es una consecuencia del iusnaturalismo ya que se sostiene gracias a los conceptos de prudencia, razón, templanza y justicia. La sociedad civil está posicionada entre lo privado y el Estado y la democracia participativa representa un instrumento por el cual el aparato estatal y los ciudadanos se vinculan y se hace posible que el Estado funcione. La democracia, sus principios y valores, debe estar presente no solamente en la forma de gobierno o en el régimen político, sino también en la forma de vida y debe ser acorde con la libertad de expresión y con la participación ciudadana; ésta última debe incluir la observación, vigilancia y la sanción a conductas antidemocráticas. Con todo lo anterior surge la posibilidad de que haya ciudadanos sancionadores de las conductas no democráticas de los demás ciudadanos. La argumentación es una práctica inherente a la libertad de expresión sustentada por la observación y vigilancia, lo que produce la discusión y deliberación de las ideas, y si lo anterior está referido a los asuntos de Estado, entonces los entes que lo ejecutan tienen también la posibilidad 
de emitir un juicio democrático y sancionar las conductas antidemocráticas. La reunión entre ciudadanos (y su libertad garantizada constitucionalmente) da la posibilidad de participar en la contrastación de ideas y en la crítica de posturas, lo que a su vez produce argumentos y razonamientos entre ciudadanos iguales: la ciudadanía vigilando a los gobernantes y a la misma ciudadanía, lo cual es un juicio democrático contra la pasividad democrática y electoral en México.

\title{
A JUStanutralist (AND SANCTIONING) THESis TO ERADiCATE THE DEMOCRATIC AND ELECTORAL PASSIVITY IN MEXICO
}

\begin{abstract}
The ius-positivism indicates that there must be sanction before the omission of ordered conducts and the iusnaturalists thesis indicate that the right thing before an obligation is that its breach is sanctioned. In accordance with the constitutional mandate, the vote is an obligation, therefore, there must be a sanction for non-compliance. However, in Mexico there is no such sanction and there is a high rate of electoral passivity (not only electoral abstention, which is a kind of democratic passivity), therefore, as a way to solve the problem, the thesis consisting of applying the sanction that should justly apply in the case of non-compliance with the obligation to cast a vote, the aforementioned based on the foundations of natural law translated into democratic judgment, and thereby even satisfy the categories of prudence, temperance and peace.
\end{abstract}

Keywords: Ius-naturalism, ius-positivism, democracy, democratic passivity, elections.

\section{FUENTES DE INFORMACIÓN}

ARISTÓTELES. Ética nicomaquea. Editorial Porrúa, colección “Sepan cuántos ...”, núm. 70, México, 2004.

BALBUENA Cisneros, Armind y Fragoso Lugo, Lucero. Las figuras de la participación ciudadana en México. En: Revuelta Vaquero, Benjamín y Patrón Sánchez Fernando, (coords.), "Democracia Participativa. Visiones, avances y provocaciones", México, Universidad de Guanajuato, Instituto Federal Electoral, Universidad Michoacana de 
San Nicolás de Hidalgo, 2010.

BIN, Elisa. Algunas reflexiones para el debate acerca de la construcción de la Democracia participativa. En: Romero, Ricardo (Comp.), "Democracia participativa, una utopía en marcha. Reflexiones experiencias y análisis del caso porteño", Buenos Aires: Red Argentina de Ciencia Política Mariano Moreno, 2005, en línea: http://bibliotecavirtual.clacso.org.ar//ar/libros/libros/gedep.pdf, consultada el 1 de diciembre del 2018.

Cámara de Diputados, H. Congreso de la Unión. Constitución Política de los Estados Unidos Mexicanos, en línea: http://www.diputados.gob.mx/LeyesBiblio/pdf/__270818.pdf, consultado el 9 de diciembre de 2018.

CARBONELL, Miguel. El fundamento a la libertad de expresión en la democracia constitucional. En: Vázquez, Ramos, Homero (coord.), "Cátedra Nacional de Derecho Jorge Carpizo. Reflexiones Constitucionales", México, Instituto de Investigaciones Jurídicas de la UNAM, 2012.

COPPEDGE, Michael. Party system, gobernability and the cuality of democracy in Latin America. Ensayo preparado para la conferencia sobre "Representation and democratic politics in Latin America", buenos Aires, Universidad de San Andrés/University of Pittsburg, 7-8 de junio de 2001.

DAHL, Robert. On democracy. New Haven, Yale University Press, 1998.

HABERMAS, Jürgen. Facticidad y validez. 4a edición, editorial Trotta; 2005.

Instituto Nacional Electoral (INE). Cómputos distritales 2018. Elecciones federales. Consultado de: https:// computos2018.ine.mx/\#/presidencia/nacional/1/1/1/1, fecha de consulta: 23 de septiembre de 2018. LINZ, Juan y Stepan, Alfred. Problems of democratic transition and consolidation. Southern Europe, South America, and post-communist Europe. Baltimore, John Hopkins University Press, 1996.

MONTESQUIEU. Del espíritu de las leyes. Editorial Porrúa, colección “Sepan cuántos ...”, núm. 191, México, 2005.

MORLINO, Leonardo. Calidad de la democracia. Notas para su discusión. Ponencia del Congreso Anual de Ciencia Política, Sociedad Italiana, Trento, 2003. 
PAVARINI, Massimo et. al. Seguridad pública. Tres puntos de vista convergentes. México, Alter libros/Ediciones Coyoacán/CONACYT/FLACUD, 2006.

PLATÓN. La República. Editorial Porrúa, colección “Sepan cuántos ...”, núm. 13B, México, 2001.

PLATÓN. Las leyes. Editorial Porrúa, colección “Sepan cuántos ...”, núm. 139, México, 1998.

ROUSSEAU, Juan Jacobo. El contrato social. Editorial Porrúa, colección “Sepan cuántos ...”, núm. 113, México, 2004.

SAN AGUSTÍN. La ciudad de dios. Editorial Porrúa, colección “Sepan cuántos ...”, núm. 59, México, 2004.

SCHUMPETER, Joseph. Capitalism, socialism and democracy. San Francisco, Harper and Row, 1976.

SEARA Vázquez, Modesto. La Sociedad Democrática. Primera parte. Universidad Nacional Autónoma de México, 1978.

TOMÁS DE AQUINO. Tratado de la ley. Editorial Porrúa, colección “Sepan cuántos ...", núm. 301, México, 2004.

TOURAINE, Alain. ¿Qué es la democracia? Fondo de Cultura Económica, México, 2004.

VALADÉS, Diego. Problemas constitucionales del Estado de Derecho. Astrea, Argentina, 2a edición, 2004.

Vanguardia.mx. Cuesta caro el abstencionismo en México. 04 de marzo de 2018, en línea: https://vanguardia.com.mx/articulo/cuesta-caro-mexico-el-abstencionismo, fecha de consulta: 12 de diciembre de 2018.

Trabalho enviado em 11 de janeiro de 2019

Aceito em 03 de fevereiro de 2019 